\title{
HUBUNGAN POLA MAKAN DENGAN KEJADIAN HIPERTENSI DI WILAYAH KERJA PUSKESMAS KEBUN SIKOLOS KOTA PADANG PANJANG TAHUN 2019
}

\author{
Abdi Iswahyudi Yasril', Widya Rahmadani ${ }^{2}$ \\ (1,2Program Studi IImu Kesehatan Masyarakat, Universitas Fort De Kock)
}

\begin{abstract}
Hypertension is a non-communicable disease. This continues to increase from year to year, and can lead to various other chronic diseases. This study aims to analyze the effect of diet on hypertension in 2019. This type of research is an observational analytic study with a prospective cohort study design. The population in this study were all adults (26 - 45 years) at the Puskesmas Kebun Sikolos. By means of purposive random sampling, a sample of 110 respondents was selected. The data obtained were processed by computerization using the Chi-square test and the Mantel Haenszel test. Chi-square test results showed that there was a relationship between salt consumption $(p=0.004$ and $R R=1.521)$, fat $(p=0.008$ and $R R$ $=1.464)$, fiber $(p=0.014$ and $R R=2.047)$ and caffeine $(p=0.012$ and $R R=1.438)$ against hypertension. The coat-Haenszel test results showed that age, gender, family history, physical activity, smoking habits, and obesity were confounding factors in the relationship between diet and hypertension. It can be concluded that the main factor that is closely related to hypertension is salt consumption. It is advisable to provide an understanding to the public about the risk of frequent salt consumption which causes hypertension to be very beneficial.
\end{abstract}

Keywords: Consumption of Salt; Fat; Fiber; Caffeine; Hypertension

\begin{abstract}
Abstrak
Hipertensi merupakan penyakit tidak menular. Hal tersebut terus meningkat dari tahun ke tahun, dan dapat memicu berbagai penyakit kronis lainnya. Penelitian ini bertujuan untuk menganalisis pengaruh pola makan terhadap hipertensi pada tahun 2019. Jenis penelitian ini adalah analitik observasional dengan desain studi kohort prospektif. Populasi dalam penelitian ini adalah seluruh orang dewasa (26 - 45 tahun) di Puskesmas Kebun Sikolos. Dengan cara purposive random sampling, sampel dipilih sebanyak 110 responden. Data yang diperoleh diolah dengan komputerisasi menggunakan uji Chi-square dan Mantel Haenszel. Hasil uji Chi-square menunjukkan bahwa ada hubungan antara konsumsi garam $(p=0,004$ dan $R R=1,521)$, lemak $(p=0,008$ dan $R R=1,464)$, serat $(p=0,014$ dan $R R=$ $2,047)$ dan kafein $(p=0,012$ dan $R R=1.438)$ terhadap hipertensi. Hasil uji Mantel-Haenszel didapatkan bahwa umur, jenis kelamin, riwayat keluarga, aktivitas fisik, kebiasaan merokok, dan obesitas merupakan faktor perancu dalam hubungan pola makan dan hipertensi. Dapat disimpulkan bahwa faktor utama yang berhubungan erat dengan hipertensi adalah konsumsi garam. Disarankan perlu diberikan pemahaman kepada masyarakat tentang risiko seringnya konsumsi garam yang menyebabkan hipertensi akan sangat bermanfaat.
\end{abstract}

Kata Kunci : Konsumsi Garam; Lemak; Serat; Kafein; Hipertensi 


\section{PENDAHULUAN}

Hipertensi merupakan penyakit tidak menular yang sering ditemukan ditengah masyarakat dan mengakibatkan angka kesakitan yang tinggi. Saat ini hipertensi telah menjadi masalah global karena prevalensinya yang terus meningkat dari tahun ke tahun. Penyakit ini dapat memicu berbagai penyakit kronis lainnya sehingga penanganannya harus segera dilakukan sebelum komplikasi dan akibat buruk lainnya terjadi ${ }^{1}$. Jumlah penyandang hipertensi terus meningkat setiap tahunnya, diperkirakan pada tahun 2025 akan ada 1,5 Miliar orang yang terkena hipertensi, dan diperkirakan setiap tahunnya 9,4 juta orang meninggal akibat hipertensi dan komplikasinya ${ }^{2}$

Di Indonesia berdasarkan data Riskesdas 2018, prevalensi hipertensi di Indonesia sebesar 31,4\%. Prevalensi tertinggi terjadi Kalimantan Selatan (44,1\%) dan yang terendah di Papua $(22,2 \%)^{3}$. Sedangkan untuk prevalensi hipertensi di Provinsi Sumatera Barat sudah mencapai $23,0 \%{ }^{7}$, walaupun prevalensi Sumbar masih dibawah Indonesia, Hipertensi masih menjadi permasalahan yang cukup serius sehingga masih perlu dilakukan pengendalian. Data Dinas Kesehatan Kota Padang Panjang Tahun 2017 menunjukkan bahwa hipertensi merupakan penyakit terbanyak urutan kedua dengan jumlah kunjungan kasus sebanyak 4.846 kasus. Angka kejadian ini dilihat dari 4 puskesmas yang ada di Kota Padang Panjang. Berdasarkan data yang ada, angka kejadian hipertensi tertinggi terdapat di Puskesmas Kebun Sikolos dengan jumlah sebanyak 2.981 kunjungan kasus ${ }^{4,5}$.

Hipertensi atau tekanan darah tinggi adalah suatu peningkatan abnormal tekanan darah dalam pembuluh darah arteri secara terus-menerus lebih dari suatu periode ${ }^{18}$. Seseorang dikatakan hipertensi apabila mengalami peningkatan tekanan darah sistolik $\geq 140 \mathrm{mmHg}$ dan tekanan darah diastolik $\geq 90 \mathrm{mmHg}$ pada dua kali pengukuran dengan selang waktu lima menit dalam keadaan cukup istirahat/tenang ${ }^{21}$. Hipertensi merupakan suatu penyakit degeneratif yang disebut juga sebagai The Silent Killer (pembunuh diam-diam) karena tidak memiliki gejala pasti. Faktor risiko penyebab kejadian hipertensi dapat dibagi menjadi 2 yaitu faktor yang tidak dapat diubah (seperti umur, jenis kelamin, genetik, dan lain-lain) dan faktor yang dapat diubah seperti (pola makan, kebiasaan merokok, kurangnya aktivitas fisik, dan lain-lain $)^{21}$. Sedangkan berdasarkan teori yang ada, penyebab hipertensi dapat dibagi menjadi 2 yaitu hipertensi esensial (primer) dan hipertensi sekunder. Hipertensi esensial (primer) tidak memiliki etiologi yang jelas dan sering dihubungkan dengan faktor gaya hidup yang buruk seperti pola makan (konsumsi garam dan lemak yang sering, konsumsi serat jarang, konsumsi kafein $)^{6}$.

Hipertensi dapat dicegah dengan melakukan perilaku hidup sehat untuk menjaga nilai tekanan darah tetap dalam kondisi normal. Beberapa perilaku hidup sehat yang bisa dilakukan antara lain yaitu menerapkan diet DASH (Dietary Approaches to Stop Hypertension) untuk mewujudkan perilaku makan sehat aktif beraktivitas fisik, 
mempertahankan bobot badan norma, berhenti merokok, dan manajemen stres. Kejadian berulang hipertensi dapat dicegah dan ditunda dengan tetap melakukan perilaku hidup sehat meski tekanan darah dalam kondisi normal ${ }^{13,14}$.

Kebiasaan hidup masyarakat di sekitar puskesmas kebun sikolos berdasarkan survey awal dari 15 orang, 11 orang sangat menyukai rasa asin dan mengkonsumsi makanan bergaram tinggi hampir setiap hari. Jika dilihat dari konsumsi lemak, 13 orang menyatakan bahwa mereka menyukai makan-makanan bersantan dan mengkonsumsi makanan gorengan dan berlemak setiap hari. Tujuan dari penelitian ini adalah untuk menganalisis hubungan pola makan terhadap kejadian hipertensi di wilayah kerja Puskesmas Kebun Sikolos Kota Padang Panjang tahun 2019. Variabel pola makan pada penelitian ini terdiri dari konsumsi garam, konsumsi lemak, konsumsi serat, dan konsumsi kafein. Selain itu, penelitian ini juga bertujuan untuk menganalisis kontribusi variabel yang diduga sebagai perancu (usia, jenis kelamin, riwayat keluarga, aktivitas fisik, kebiasaan merokok, dan obesitas) terhadap hubungan konsumsi garam, konsumsi lemak, konsumsi serat, dan konsumsi kafein.

\section{METODE PENELITIAN}

Jenis penelitian yang digunakan adalah observasional analitik dengan desain studi kohort prospektif suatu penelitian untuk menilai hubungan kausal antara paparan dengan menetapkan kelompok subjek dengan efek negatif (orang yang sehat). Selanjutnya, subjek dikelompokkan berdasarkan status paparannya (faktor risiko) yaitu faktor risiko positif dan faktor risiko negatif. Kemudian, kelompok ini diikuti sepanjang kurun waktu tertentu hingga efek muncul. Paparan yang diukur kemudian digunakan untuk menentukan prediktor bagi timbulnya efek ${ }^{11}$. Lokasi penelitian adalah diwilayah kerja Puskesmas Kebun Sikolos. Waktu penelitian dilaksanakan selama 2 bulan dari bulan Februari hingga April 2019. Populasi penelitian adalah seluruh masyarakat usia dewasa ( 26 - 45 tahun) yang berada di wilayah kerja Puskesmas Kebun Sikolos dan tidak menderita hipertensi pada tahun 2019 sebanyak 8.428 orang. Jumlah sampel sebanyak 110 orang dan teknik yang digunakan untuk pengambilan sampel adalah teknik purposive random sampling.

Variabel penelitian terdiri dari variabel bebas, variabel terikat. Variabel bebas yaitu kejadian hipertensi. Sedangkan variabel terikat yaitu pola makan yang terdiri dari konsumsi garam, konsumsi lemak, konsumsi serat, dan konsumsi serat. Untuk variabel perancu antara lain usia, jenis kelamin, riwayat keluarga, aktivitas fisik, kebiasaan merokok, dan obesitas. Kejadian hipertensi diukur menggunakan alat Sfigmomanometer digital, data pola makan dikumpulkan dengan Food Frequency Questionnaire (FFQ).

Data dianalisis secara univariat dan bivariat. Analisis univariat untuk mendeskripsikan karakteristik data pada setiap variabel penelitian yang ditampilkan menggunakan distribusi 
frekuensi dan proporsi data. Analisis bivariat bertujuan untuk mengetahui adanya hubungan di antara dua variabel yang diteliti. Uji statistik yang digunakan adalah Chi-square dengan koreksi lanjutan Continuity Correction pada tingkat kemaknaan $\alpha=0,05$.

\section{HASIL PENELITIAN}

Tabel 1. Distribusi Frekuensi Karakteristik Responden pada Kejadian

\begin{tabular}{ccc} 
Hipertensi & Frekuensi & Persentase (\%) \\
\hline Variabel & & \\
Usia & 33 & 30,0 \\
Dewasa awal & 77 & 70,0 \\
Dewasa akhir & 110 & 100 \\
Total & 41 & 37,3 \\
\hline Jenis Kelamin & 69 & 62,7 \\
Laki-laki & 110 & 100 \\
Perempuan & & \\
Total & 88 & 80,0 \\
Riwayat Keluarga & 22 & 20,0 \\
Tidak Ada & 110 & 100 \\
Ada & & \\
Total & 48 & 43,6 \\
Aktifitas Fisik & 62 & 56,4 \\
Sedang & 110 & 100 \\
Berat & & 25,5 \\
Total & 28 & 74,5 \\
Tidak & 82 & 100 \\
Ya & 110 & 91,8 \\
Total & 101 & 8,2 \\
Tidak & 9 & 100 \\
Ya & 110 & \\
Total & & \\
\hline Obesiasaan Merokok & & \\
\hline
\end{tabular}

Pada tabel 1 dapat diketahui bahwa sebagian responden berusia dewasa akhir (70,0\%), perempuan $(62,7 \%)$, tidak ada riwayat keluarga hipertensi $(80,0 \%)$, aktivitas fisik berat $(56,4 \%)$, memiliki kebiasaan merokok $(74,5 \%)$, tidak obesitas $(91,8 \%)$. Kemudian untuk meilhat distribusi frekuensi pola makan pada kejadian hipertensi dapat dilihat pada tabel 2 yaitu pola makan terdiri dari konsumsi garam, konsumsi lemak, konsumsi serat dan konsumsi kafein. 
Tabel 2. Distribusi Frekuensi Pola Makan pada Kejadian Hipertensi

\begin{tabular}{ccc}
\hline Konsumsi Garam & Frekuensi & Persentase (\%) \\
\hline Jarang & 54 & 49,1 \\
Sering & 56 & 50,9 \\
Total & 110 & 100 \\
\hline Konsumsi Lemak & 52 & 47,3 \\
Jarang & 58 & 52,7 \\
Sering & 110 & 100 \\
Total & & \\
Konsumsi Serat & 51 & 46,4 \\
Jarang & 59 & 53,6 \\
Sering & 110 & 100 \\
Total & & \\
Konsumsi Kafein & 54 & 49,1 \\
Jarang & 56 & 50,9 \\
Sering & 110 & 100 \\
Total & & 67,3 \\
Tidak & 74 & 32,7 \\
Ya & 36 & 100 \\
Total & 110 &
\end{tabular}

Pada tabel 2 diperoleh data responden sering mengkonsumsi garam sebesar 56 responden $(50,9 \%)$, hal ini dkarenakan kesadaran masyarakat untuk membatasi diri dalam mengkonsumsi garam dapat dikatakan masih kurang, kemudian responden juga sering mengkonsumsi lemak yaitu 58 responden $(52,7 \%)$ artinya masyarakat banyak menyukai makanan yang berbahan baku daging baik daging ayam ataupun sapi, makanan gorengan, makanan bersantan dan lain-lain. Kemudian responden juga sering mengkonsumsi makanan berserat yaitu 59 responden (53,6\%) namun diketahui bahwa kebanyakan responden memiliki pola makan yang cenderung rendah serat. Banyak responden yang mengaku bahwa mereka hanya mengkonsumsi beberapa sendok sayuran saja.

Sementara itu masih ada yang sering konsumsi kafein yaitu 56 responden (50,9\%) karena mereka memiliki kebiasaan rutin dalam mengkonsumsi kopi ataupun teh setiap harinya sehingga dapat mempunyai efek pada takanan darah. dan sesuai dengan data diperoleh responden tidak hipertensi ada 74 responden (67,3\%) dan responden yang memiliki hipertensi sebanyak 36 responden (32,7\%). Hipertensi merupakan suatu penyakit yang dapat disebabkan oleh multifaktor. Penyakit hipertensi dapat dicegah jika dilakukan pengendalianSemakin lama seseorang terpapar dengan faktor risiko maka orang tersebut semakin berisiko pula untuk mengalami kejadian hipertensi. 


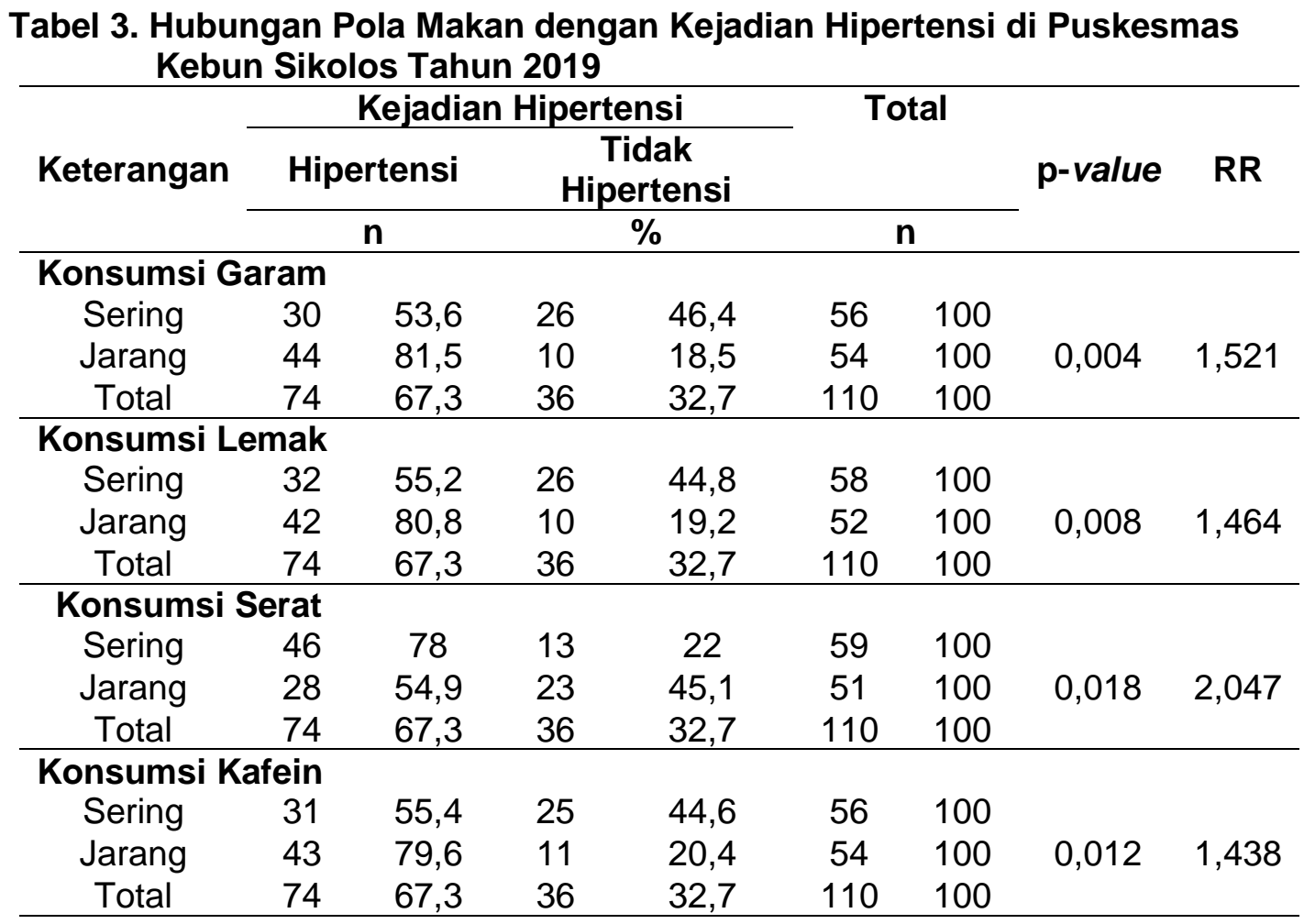

Berdasarkan hasil penelitian dapat diketahui bahwa ada hubungan yang signifikan antara konsumsi garam ( $p=0,004 ; R R=1,521)$ artinya ada hubungan antara konsumsi garam dengan kejadian hipertensi pada masyarakat di wilayah kerja Puskesmas Kebun Sikolos Kota Padang Panjang Tahun 2019 dengan nilai $R R=1,521$ yang artinya orang yang jarang mengkonsumsi garam memiliki peluang 2 kali lebih besar untuk tidak mengalami kejadian hipertensi dibandingkan dengan orang yang sering mengkonsumsi garam. Kemudian konsumsi lemak ( $p=0,008 ; R R=1,464)$ artinya ada hubungan antara konsumsi lemak dengan kejadian hipertensi pada masyarakat dan didapatkan hasil $R R=1,464$, artinya orang yang jarang mengkonsumsi lemak memiliki peluang 1,5 kali lebih besar untuk tidak mengalami kejadian hipertensi dibandingkan dengan orang yang sering mengkonsumsi lemak.

Konsumsi serat $(p=0,018 ; R R=2,047)$ artinya ada hubungan antara konsumsi serat dengan kejadian hipertensi pada masyarakat dan $R R=2,047$ artinya orang yang sering mengkonsumsi serat memiliki peluang 2 kali lebih besar untuk mengalami kejadian hipertensi dibandingkan dengan orang yang jarang mengkonsumsi serat, dan konsumsi kafein ( $p=0,012 R R=1,438$ ) yang berarti bahwa ada hubungan antara konsumsi kafein dengan kejadian hipertensi pada masyarakat di wilayah kerja Puskesmas Kebun Sikolos Kota Padang Panjang Tahun 2019 dan didapatkan hasil $R R=1,438$, artinya orang yang jarang mengkonsumsi kafein memiliki peluang 1 kali lebih besar untuk tidak mengalami kejadian hipertensi dibandingkan dengan orang yang sering mengkonsumsi kafein. 


\section{PEMBAHASAN}

\section{Hubungan Konsumsi Garam dengan Kejadian Hipertensi}

Berdasarkan hasil penelitian diketahui bahwa Hasil uji statistik didapatkan $\mathrm{p}$ value $(0,004)$ berarti ada hubungan antara konsumsi garam dengan kejadian hipertensi pada masyarakat di wilayah kerja Puskesmas Kebun Sikolos Kota Padang Panjang Tahun 2019 dengan nilai $R R=1,521$ yang artinya orang yang jarang mengkonsumsi garam memiliki peluang 2 kali lebih besar untuk tidak mengalami kejadian hipertensi dibandingkan dengan orang yang sering mengkonsumsi garam. Garam berfungsi sebagai nutrisi penting dalam tubuh dan membantu saraf dan otot berfungsi dengan benar. Garam juga terlibat dalam pengaturan air secara otomatis dan keseimbangan cairan dalam tubuh. Asupan garam diet yang tinggi merupakan tantangan besar bagi ginjal untuk mengeluarkan jumlah besar garam yang diberikan. Salah satu sistem organ utama yang rentan terhadap efek buruk dari garam yang berlebihan di diet adalah sistem kardiovaskular. Kelebihan garam diet predisposisi terhadap tekanan darah tinggi ${ }^{10,12}$.

Hasil penelitian ini sejalan dengan penelitian yang dilakukan Agustin \& Raharjo (2015) yang menyatakan bahwa terdapat hubungan antara konsumsi garam dengan kejadian hipertensi dengan $\mathrm{p}$ value $=0,004$ dan $\mathrm{OR}=5,675$ yang artinya bahwa orang yang sering mengkonsumsi garam memiliki risiko 6 kali mengalami hipertensi dibandingkan orang yang jarang mengkonsumsi garam ${ }^{1}$. Hasil penelitian ini juga sejalan dengan penelitian yang dilakukan oleh Dong (2018) yang menyatakan bahwa terdapat hubungan antara konsumsi garam dengan kejadian hipertensi. Hasil $p$ value yang didapatkan yaitu 0,042 dengan nilai $\mathrm{OR}=1,73$ yang artinya orang yang mengkonsumsi garam tinggi memiliki risiko 2 kali lebih besar untuk mengalami hipertensi dibandingkan orang yang tidak mengkonsumsi garam tinggi ${ }^{8}$

Masyarakat cenderung menyukai makanan-makanan yang banyak mengandung garam seperti sering mengkonsumsi ikan asin, ikan laut (ikan tongkol, ikan teri, ikan kakap), sarden, dan lain-lain. Selain itu, masyarakat juga sering memakan makanan yang banyak mengandung penyedap rasa seperti bakso dan mie ayam sehingga intensitas masyarakat dalam mengkonsumsi makanan yang banyak mengandung garam cenderung tinggi yang dapat meningkatkan kejadian hipertensi. Oleh karena itu masyarakat diharapkan dapat mengontrol konsumsi garam agar seimbang sehingga dapat meminimalisir terjadinya hipertensi.

\section{Hubungan Konsumsi Lemak dengan Kejadian Hipertensi}

Berdasarkan hasil penelitian diketahui bahwa $p$-value $(0,008<0,05)$ berarti ada hubungan antara konsumsi lemak dengan kejadian hipertensi pada masyarakat di wilayah kerja Puskesmas Kebun Sikolos Kota Padang Panjang Tahun 2019 dan didapatkan hasil 
$R R=1,464$, artinya orang yang jarang mengkonsumsi lemak memiliki peluang 1,5 kali lebih besar untuk tidak mengalami kejadian hipertensi dibandingkan dengan orang yang sering mengkonsumsi lemak. Konsumsi tinggi lemak dapat menyebabkan tekanan darah meningkat. Konsumsi lemak yang berlebihan akan meningkatkan kadar kolesterol dalam darah terutama kolesterol LDL dan akan tertimbun dalam tubuh. Timbunan lemak yang disebabkan oleh kolesterol akan menempel pada pembuluh darah yang lama-kelaman akan terbentuk plaque. Terbentuknya plaque dapat menyebabkan penyumbatan pembuluh darah atau aterosklerosis. Pembuluh darah yang terkena aterosklerosis akan berkurang elastisitasnya dan aliran darah ke seluruh tubuh akan terganggu serta dapat memicu meningkatnya volume darah dan tekanan darah. Meningkatnya tekanan darah tersebut dapat mengakibatkan terjadinya hipertensi ${ }^{16}$.

Hasil penelitian ini sejalan dengan penelitian yang dilakukan oleh Kartika, et al., (2016) dalam jurnal gizi dan dietetik Indonesia juga menyatakan bahwa terdapat hubungan antara konsumsi lemak dengan kejadian hipertensi dengan $p$ value $=0,009$ dan $\mathrm{OR}=3,839$ yang artinya penduduk yang mengkonsumsi makanan berlemak mempunyai risiko hipertensi 4 kali dibanding penduduk yang tidak mengkonsumsi makanan berlemak ${ }^{9}$. Orang yang beretnis Minangkabau cenderung sangat menyukai makan makanan yang berlemak seperti makanan bersantan, makanan goreng- gorengan, dan lain-lain. Berdasarkan hasil observasi dilapangan dapat diketahui bahwa umumnya masyarakat sering memakan makanan yang mengandung santan seperti gulai, asam padeh, dan lain-lain. Kemudian masyarakat juga mengaku sering mengkonsumsi goreng-goreng yang dibuat sendiri ataupun dibeli baik untuk dijadikan lauk pauk seperti ayam goreng dan ikan goreng ataupun dijadikan cemilan seperti pisang goreng, tempe goreng, dan tahu goreng. Oleh karena itu, perlunya kesadaran masyarakat dalam mengkonsumsi lemak agar tidak berlebihan sehingga dapat mengurangi risiko terjadinya hipertensi.

\section{Hubungan Konsumsi Serat dengan Kejadian Hipertensi}

Berdasarkan hasil penelitian bahwa $\mathrm{p}$ value $(0,018)<\alpha(0,05)$, berarti ada hubungan antara konsumsi serat dengan kejadian hipertensi pada masyarakat di wilayah kerja Puskesmas Kebun Sikolos Kota Padang Panjang Tahun 2019 dan didapatkan hasil RR = 2,047, artinya orang yang sering mengkonsumsi serat memiliki peluang 2 kali lebih besar untuk mengalami kejadian hipertensi dibandingkan dengan orang yang jarang mengkonsumsi serat. Asupan serat berhubungan dengan terjadinya tekanan darah tinggi karena asupan serat dapat membantu meningkatkan pengeluaran kolesterol melalui feses dengan jalan meningkatkan waktu transit bahan makanan melalui usus. Mengkonsumsi serat sangat menguntungkan karena dapat mengurangi pemasukan energi dan obesitas yang pada akhirnya menurunkan risiko penyakit tekanan darah tinggi22. 
Hasil penelitian ini sejalan dengan penelitian yang dilakukan oleh Anwar (2015) yang menyatakan bahwa terdapat hubungan antara konsumsi serat dengan kejadian hipertensi dengan $p$ value $=0,005$ dan $O R=5,30$ yang artinya orang yang mengkonsumsi serat cukup jarang berisiko 5,30 kali mengalami hipertensi dibandingkan orang yang lebih sering mengkonsumsi serat ${ }^{19}$. Selain itu, hasil penelitian ini juga sejalan dengan penelitian yang dilakukan oleh Birlew \& Alemseged (2015) dalam Science Journal of Public Health yang menyatakan bahwa terdapat hubungan antara konsumsi serat dengan kejadian hipertensi. Hasil $p$ value didapatkan yaitu $<0,005$ dengan nilai $O R=1,76$. Sehingga dapat disimpulkan bahwa orang yang jarang mengkonsumsi serat berisiko 1,76 kali untuk mengalami hipertensi dibandingkan dengan orang yang sering mengkonsumsi serat ${ }^{20}$.

Umumnya masih banyak masyarakat yang jarang untuk mengkonsumsi makanan berserat yaitu buah-buahan dan sayuran. Mereka mengaku bahwa mereka sangat jarang sekali memakan buah-buahan. Sedangkan untuk sayuran masyarakat umumnya mengaku bahwa mereka hanya memakan sayuran $1-2$ kali dalam seminggu dengan jumlah yang sedikit. Bahkan beberapa dari masyarakat juga ada yang menyatakan bahwa mereka tidak menyukai sayur-sayuran. Buah dan sayuran merupakan salah satu sumber makanan yang sangat bermanfaat bagi tubuh. Sehingga, diharapkan kepada masyarakat agar dapat meningkatkan frekuensi konsumsi serat setiap harinya.

\section{Hubungan Konsumsi Kafein Dengan Kejadian Hipertensi}

Berdasarkan hasil penelitian $\mathrm{p}$ value $(0,012)<\alpha(0,05)$, berarti ada hubunga antara konsumsi kafein dengan kejadian hipertensi pada masyarakat di wilayah kerja Puskesmas Kebun Sikolos Kota Padang Panjang Tahun 2019 dan didapatkan hasil $R R=1,438$, artinya orang yang jarang mengkonsumsi kafein memiliki peluang 1 kali lebih besar untuk tidak mengalami kejadian hipertensi dibandingkan dengan orang yang sering mengkonsumsi kafein.Tekanan darah biasanya meningkat dalam waktu 30 menit dan semakin meningkat maksimal selama 60 sampai 120 menit setelah mengkonsumsi kafein. Pengaruh kafein berbeda terhadap masing-masing orang dan lama pengaruh tergantung jumlah kafein yang dikonsumsi, jenis kelamin, atau merokok. Pengaruh kafein ini dipengaruhi oleh jumlah konsumsi kafein yang masuk ke dalam tubuh seseorang. Konsumsi yang berlebih dan dilakukan setiap hari sebagai pola hidup sehari-hari tentunya akan membuat terjadinya akumulasi dampak kafein pada tubuh sehingga salah satunya terjadi risiko peningkatan tekanan darah ${ }^{13,17}$.

Hasil penelitian ini sejalan dengan penelitian yang dilakukan oleh Rachmawati (2016) yang menyatakan terdapat hubungan antara konsumsi kafein dengan kejadian hipertensi dengan $\mathrm{p}$ value $=0,000$ dan $\mathrm{OR}=1,33$ yang artinya penduduk yang sering mengkonsumsi kafein mempunyai risiko hipertensi 1,33 kali dibandingkan penduduk yang jarang 
mengkonsumsi kafein ${ }^{15}$. Peneliti berasumsi bahwa hubungan antara konsumsi kafein dengan kejadian hipertensi berdasarkan hasil observasi dilapangan disebabkan oleh banyaknya masyarakat yang rutin meminum kopi. Bukan hanya laki-laki, namun sekarang ini para perempuan pun juga sering mengkonsumsi kopi. Masyarakat laki-laki umumnya mengatakan bahwa mereka meminum kopi dengan frekuensi 2 - 3 gelas setiap hari. Sedangkan masyarakat perempuan mengatakan bahwa mereka mengkonsumsi kopi dengan frekuensi 1 gelas sehari atau 3 gelas dalam seminggu. Selain itu, masyarakat juga mengatakan bahwa kopi yang mereka konsumsi kebanyakan adalah kopi hitam. Oleh karena itu, diharapkan kepada masyarakat untuk dapat mengurangi konsumsi kafein yang berlebihan sehingga dapat meminimalisir kejadian hipertensi.

\section{SIMPULAN DAN SARAN}

Kesimpulan dari penelitian ini adalah faktor utama yang berhubungan erat dengan hipertensi adalah konsumsi garam. Disarankan perlu diberikan pemahaman kepada masyarakat tentang risiko seringnya konsumsi garam yang menyebabkan hipertensi akan sangat bermanfaat.

\section{DAFTAR PUSTAKA}

1. Agustina, R., \& Raharjo, B. B. (2015). Faktor Risiko Yang Berhubungan Dengan Kejadian Hipertensi Usia Produktif (25-54 Tahun). Unnes Journal of Public Health, 4, 146-157.

2. WHO. (2018). Raised Blood Pressure Situation and Trends. Jenewa: World Health Organization

3. Kemenkes RI. (2018). Hasil Utama Riskesdas 2018. Jakarta: Kementerian Kesehatan Republik Indonesia.

4. Dinkes Padang Panjang. (2017). Data 10 Penyakit Terbanyak di Kota Padang Panjang Tahun 2017. Padang Panjang: Dinas Kesehatan Kota.

5. BPS Kota Padang Panjang. (2018). Kecamatan Padang Panjang Barat Dalam Angka. Padang Panjang: Badan Pusat Statistik Kota Padang Panjang.

6. Bustan, M. N. (2015). Manajemen Pengendalian Penyakit Tidak Menular. Jakarta: Rineka Cipta.

7. Dinkes Sumatera Barat. (2017). Profil Dinas Kesehatan 2017. Padang: Dinas Kesehatan Provinsi Sumatera Barat.

8. Dong, O. M. (2018). Excessive Dietary Sodium Intake and Eleveted Blood Pressure. BMJ Nutrition, Prevention, \& Health, 1-10.

9. Kartika, L. A., Afifah, E., \& Suryani, I. (2016). Asupan Lemak dan Aktivitas Fisik serta Hubungannya Dengan Hipertensi. Jurnal Gizi dan Dietetik Indonesia, 4(3), 139-146. 
10. Kyu, S. H. (2014). Dietary Salt Intake and Hypertension. The Korean Society of Electrolyte Metabolism, 12, 7-18.

11. Notoatmodjo, S. (2010). Metodologi Penelitian Kesehatan. Jakarta: PT. Rineka Cipta.

12. Nugroho, K. P., Sanubari, T. P., \& Rumondor, J. M. (2019). Faktor Risiko Penyebab Kejadian Hipertensi Di Wilayah Kerja Puskesmas Sidorejo Lor Kota Salatiga. Jurnal Kesehatan Kusuma Husada, 32-42.

13. Pramana, L. D. (2016). Faktor-Faktor Yang Berhubungan Dengan Tingkat Hipertensi Di Wilayah Kerja Puskesmas Demak II. Fakultas Kesehatan Masyarakat. Semarang: Universitas Muhammadiyah Semarang.

14. Prasetyaningrum, Y. I. (2014). Hipertensi Bukan Untuk Ditakuti. Jakarta: FMedia.

15. Rachmawati, E. (2016). Faktor-Faktor Yang Berhubungan Dengan Hipertensi Pada Orang Dewasa Di Propinsi Jawa Tengah. Prosiding Seminar Nasional Penelitian Dan PKM Kesehatan, 6(1), 19-27.

16. Dewanti, Novita dan Nur. (2017). Pangan Fungsional. Malang : UB Press

17. Susilawati, Sety, L. O., \& Tina, L. (2018). Faktor-Faktor Yang Berhubungan Dengan Kejadian Hipertensi Pada Kelompok Usia Dewasa Muda (20-44 Tahun) Di Wilayah Kerja Puskesmas Wonggeduku Kabupaten Konawe Tahun 2017. 3(1).

18. Udjianti, W. J. (2011). Keperawatan Kardiovaskular. Jakarta: Salemba Medika.

19. Anwar, R. (2015). Konsumsi Buah dan Sayur Serta Konsumsi Susu Sebagai Faktor Risiko Terjadinya Hipertensi Di Puskesmas S. Parman Kota Banjarmasin . Jurnal Skala Kesehatan, 5(1).

20. Birlew, T., \& Alemseged, F. (2015). Risk factors for hypertension among adults. An Analysis of Survey Data on Chronic Non-Communicable Disease at Gilgel Gibe Field Research Center, South West Ethiopia. Science Journal of Public Health, 3(2), 281290.

21. Kemenkes RI. (2014). Info Datin Hipertensi. Jakarta Selatan: Kementerian Kesehatan Republik Indonesia.

22. Ahmad. (2019). Pangan, Gizi dan Kesehatan. Yogyakarta : Deepublish. 